\title{
The occupational burden of chronic obstructive pulmonary disease
}

\author{
L. Trupin*, G. Earnest", M. San Pedro", J.R. Balmes ${ }^{\#, \oplus,}$, M.D. Eisner, ${ }^{\#,}$, E. Yelin*, P.P. Katz*, \\ P.D. Blanc ${ }^{\#,+,+}$
}

The occupational burden of chronic obstructive pulmonary disease. L. Trupin, $G$ Earnest, M. San Pedro, J.R. Balmes, M.D. Eisner, E. Yelin, P.P. Katz, P.D. Blanc. (C) ERS Journals Ltd 2003.

ABSTRACT: Although chronic obstructive pulmonary disease (COPD) is attributed predominantly to tobacco smoke, occupational exposures are also suspected risk factors for COPD. Estimating the proportion of COPD attributable to occupation is thus an important public health need.

A randomly selected sample of 2,061 US residents aged 55-75 yrs completed telephone interviews covering respiratory health, general health status and occupational history. Occupational exposure during the longest-held job was determined by selfreported exposure to vapours, gas, dust or fumes and through a job exposure matrix. COPD was defined by self-reported physician's diagnosis.

After adjusting for smoking status and demography, the odds ratio for COPD related to self-reported occupational exposure was 2.0 (95\% confidence interval (CI) 1.6-2.5), resulting in an adjusted population attributable risk (PAR) of $20 \%(95 \%$ CI 13-27\%), The adjusted odds ratio based on the job exposure matrix was $1.6(95 \%$ CI 1.1-2.5) for high and $1.4(95 \%$ CI 1.1-1.9) for intermediate probability of occupational dust exposure; the associated PAR was 9\% (95\% CI 3-15\%). A narrower definition of COPD, excluding chronic bronchitis, was associated with a PAR based on reported occupational exposure of $31 \%(95 \%$ CI $19-41 \%)$.

Past occupational exposures significantly increased the likelihood of chronic obstructive pulmonary disease, independent of the effects of smoking. Given that one in five cases of chronic obstructive pulmonary disease may be attributable to occupational exposures, clinicians and health policy-makers should address this potential avenue of chronic obstructive pulmonary disease causation and its prevention. Eur Respir J 2003; 22: 462-469.
Divisions of *Rheumatology, " Occupational and Environmental Medicine and Pulmonary and Critical Care, and ${ }^{+}$Cardiovascular Research Institute, University of California, San Francisco, CA, USA.

\author{
Correspondence: L. Trupin \\ University of California \\ Box 0920 \\ San Francisco \\ CA94143-0920 \\ USA \\ Fax: 14154769030 \\ E-mail: trupin@itsa.ucsf.edu
}

Keywords: Airflow limitation chronic bronchitis

chronic obstructive pulmonary disease emphysema

occupational health

work-related

Received: October 152002

Accepted after revision: April 122003

This study was supported by the National Heart, Lung, and Blood Institute (NHLBI) of the US National Institutes of Health (HL677438). M.D. Eisner was also supported by K23 HL04201 (NHLBI).
Chronic obstructive pulmonary disease (COPD) accounts worldwide for considerable and increasing morbidity and mortality $[1,2]$. COPD is a disease state characterised by the presence of airflow limitation that is typically progressive and associated with an abnormal inflammatory response of the lungs to noxious particles or gases [3]. The term COPD subsumes several different and frequently concomitant clinical conditions, including chronic bronchitis and emphysema.

Cigarette smoking is by far the predominant risk factor for COPD. This has obscured the role of other environmental factors that might account for disease among nonsmokers or magnify the adverse impact of cigarettes among those who smoke. Recognition that the complex particulate and irritant gas constituents of tobacco smoke can cause COPD provides high biological plausibility that other inhaled toxins may also play an aetiological role in this disease process. Owing to the intensity and duration of exposure involved, the most likely candidate exposures contributing to COPD are vapours, gases, dusts or fumes (VGDF) encountered in the workplace.

"Dusty trades" have been linked to chronic bronchitis since the nineteenth century [4]. Analysis of epidemiological data from the 1930s and 1940s confirmed the impression of a strong link between occupation and chronic bronchitis $[5,6]$. Later, in the 1950s and early 1960s, irreversible airflow limitation and emphysema, which are functional and pathological abnormalities linked with chronic bronchitis, were shown to be increased among mineworkers, one of the occupational groups most heavily exposed to dust and fumes [7, 8].

Since the mid-1970s, a number of epidemiological studies have implicated occupational exposures in COPD. These investigations, summarised in the seminal 1989 review of BECKLAKE [9] and, more recently, by VIEGI and Di PEDE [10], have been carried out within specific industrial cohorts as well as across community-based population samples. Most of these population samples were developed for other research purposes; some of the studies examined only recent occupational exposures [11-13], included primarily younger adults [11-15] or covered a limited geographical area [16-19]. As a result, although there has been an accumulation of evidence linking occupational inhalant exposures to COPD, estimates of the proportion of COPD cases attributable to workplace exposures have varied widely from study to study $[9,10]$. Given the high prevalence of COPD and the preventability of occupation-related disease, establishing the occupational contribution to the burden of COPD could have a major public health impact. In this study, older adults were surveyed regarding their health status, prior cigarette smoking and history of occupational exposures. 
Methods

\section{Overview}

The contribution of occupational exposures to the prevalence of obstructive airway diseases was estimated using data from a randomly selected sample of US residents aged 55-75 yrs interviewed by telephone. The odds ratios (OR) and population attributable risks (PAR) for COPD associated with occupation- and job-related exposures were estimated after accounting for cigarette smoking. The study was approved by the University of California, San Francisco Committee on Human Research (San Francisco, CA, USA).

\section{Chronic obstructive pulmonary disease definition}

Subjects were asked whether they had ever received a physician's diagnosis of any of several chronic respiratory conditions. Those who reported diagnoses of chronic bronchitis or emphysema were considered to have COPD, along with those who specifically reported a diagnosis of COPD. A narrower definition of COPD that included only subjects reporting emphysema or COPD, excluding those with chronic bronchitis alone, was also developed. In order to avoid introducing a misclassification bias when using this narrower definition, subjects reporting chronic bronchitis alone were entirely excluded from these specific analyses, thus reducing the study number in these instances. For the main analyses, the COPD classification included respondents with and without concomitant asthma, since adults with COPD and asthma are typically more similar to adults with COPD alone than they are to those with asthma alone, in terms of demographical profile, smoking history and disease progression.

\section{Subject selection}

In order to develop the sample, sets of random telephone numbers were systematically selected across all eligible telephone blocks within a defined area. Field Research Corporation (San Francisco, CA, USA) conducted all interviews between April 28 and August 30, 2001. Initial telephone contacts were made during early evening hours and throughout the day on weekends to increase the chances of reaching both working and nonworking adults; up to six further attempts to make initial contact were made at different times of day. Interviews were conducted in either English or Spanish with one randomly selected eligible adult per contacted household.

\section{Sampling frames and recruitment}

The total sample was constructed from three cohorts based on geography and respiratory condition (fig. 1). The first cohort included 1,001 subjects recruited from a national random sample in the 48 contiguous states of the USA. The second and third cohorts were limited to certain geographical "hot spots", based on Health Service Areas with the highest COPD mortality rates, derived from the National Institute of Occupational Safety and Health's Atlas of Respiratory Disease Mortality, United States: 1982-1993 [20]. The telephone area codes corresponding best to the areas in the top
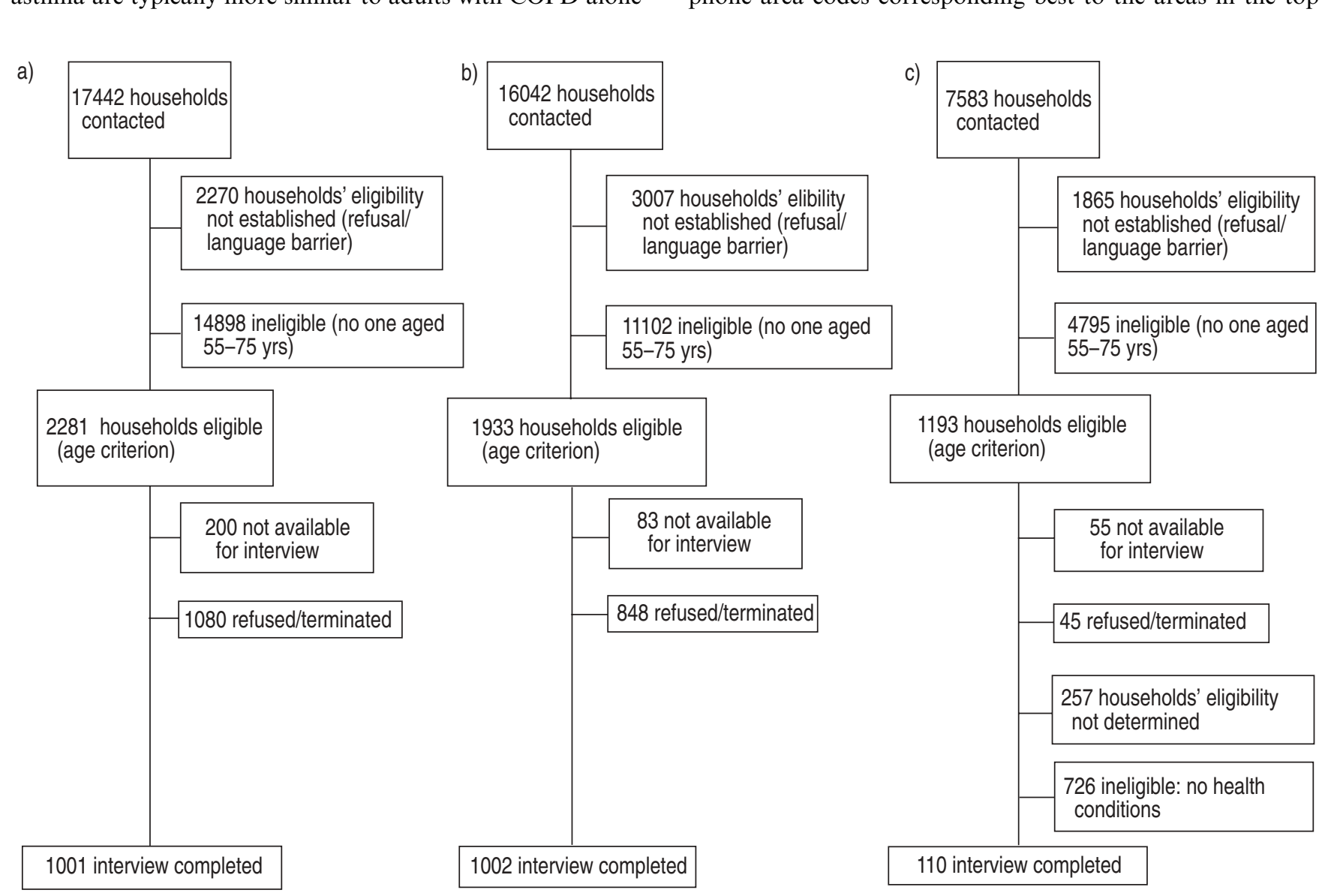

Fig. 1.-Subject recruitment in three sampling frames: a) national random sample; b) "hot spots" random sample; and c) hot spots condition sample. 


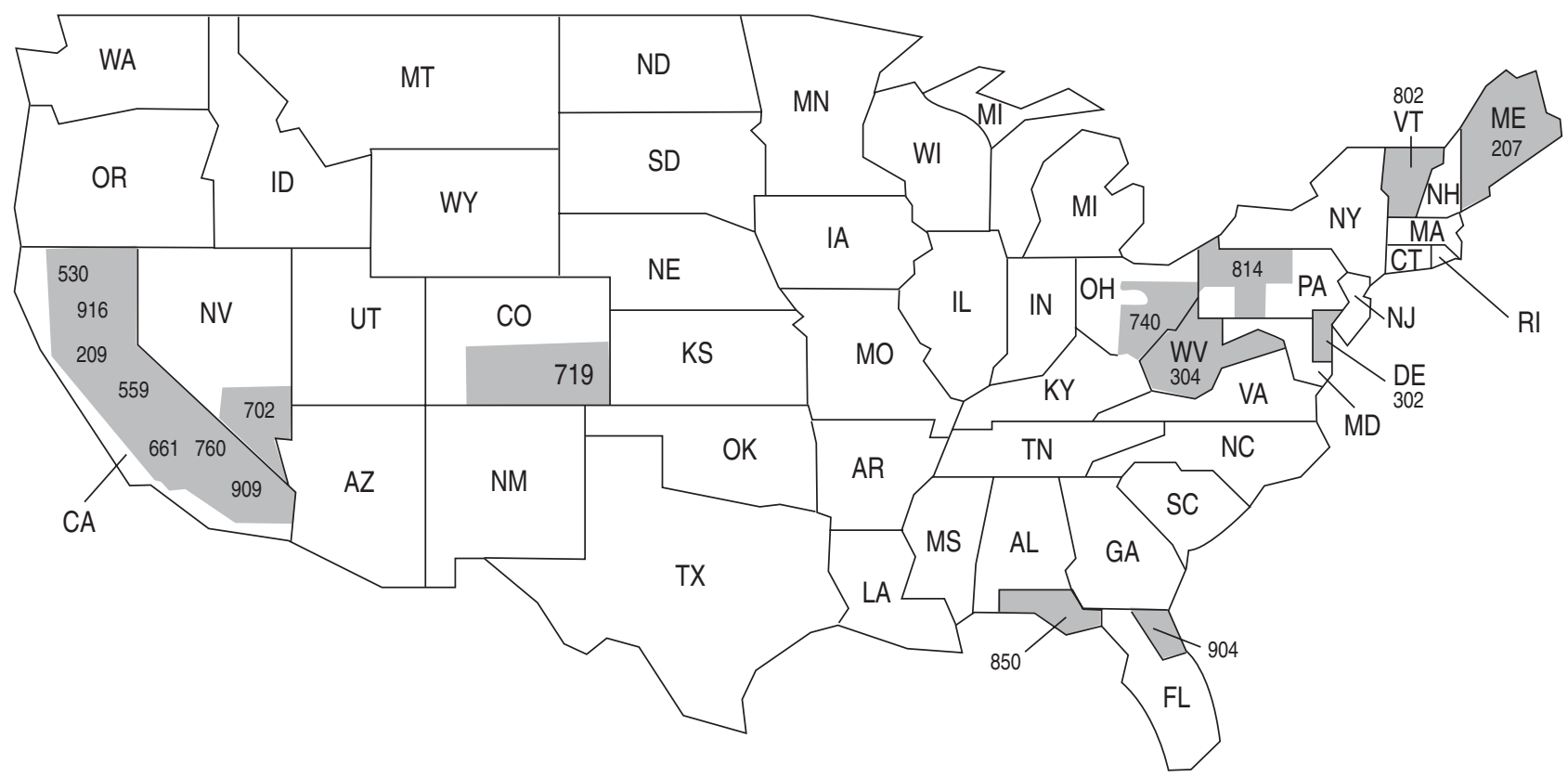

Fig. 2.-Telephone area codes $(\square)$ corresponding to the "hot spot" Health Service Areas with the highest age-adjusted chronic obstructive pulmonary disease mortality rates, 1982-1993 [20].

quartile of elevated age-adjusted mortality rates were selected (fig. 2), in order to increase the yield of individuals with COPD. The second cohort included 1,002 participants recruited through random sampling of these hot spot area codes. The third cohort included 110 respondents selected from the hot spot areas and prescreened to include only individuals reporting a physician's diagnosis of either one of the three COPD conditions or asthma. The entire sample consisted of 2,113 individuals, representing a combined response rate of $53 \%$ of households with at least one person aged 55-75 yrs, as shown in figure 1. After omitting subjects not responding to key analysis variables, the final sample included 2,061 individuals ( $98 \%$ of original sample).

\section{Survey instrument}

All participants, regardless of the cohort from which they were drawn, responded to identical telephone-based questionnaires covering: respiratory symptoms and medications; comorbid conditions and general health status; healthcare utilisation; employment history; smoking history; and demographical and socioeconomical background.

After the initial age screen to establish subject eligibility, the respiratory condition status of the respondent was established with the question "Has a medical doctor ever told you that you have any of the following medical conditions that can affect the lungs or breathing?" Respondents were asked in this manner about chronic bronchitis, emphysema, COPD and asthma; a follow-up question ascertained diagnosis dates. All respondents were also asked a series of questions about specific respiratory symptoms and a detailed list of medications and treatments typically used in COPD and asthma.

The employment section elicited information about the respondent's current or most recent job and the longest-held job. Items included open-ended questions about occupation and industry, later coded to the 2000 US census codes [21], duration of job (in years) and pattern (hours and weeks) of work, using established batteries [22]. Information about occupational exposures to VGDF was obtained for all jobs held during the respondent's working life.

\section{Classifying occupational exposure}

Respondents' occupational exposures were determined in two different ways, by self-reported exposure and through a job exposure matrix. Self-reported exposure was identified initially through a question developed for the European Community Respiratory Health Survey (ECRHS) [23]: "Have you ever worked in a job which exposed you to vapours, gas, dust, or fumes?" The question was followed by a list of 15 individual exposures considered a priori risk factors for COPD, subsequently grouped into three categories: combustion byproducts, inorganic dusts and fumes, and organic dusts. The duration of exposure (in years) in the longest-held job and across all jobs for which the respondent reported exposure was calculated.

The job exposure matrix was intended to serve as a somewhat more conservative measure than the self-reported measure. It was originally developed as part of an analysis of the ECRHS [24]. In this matrix, specific occupations were categorised as having a low, intermediate or high probability of dust exposure on an a priori basis.

\section{Smoking status and other covariates}

Respondents were grouped into three categories on the basis of smoking status: current, former, and never smokers [25]. Demographical and socioeconomical variables examined included age $(55-59,60-64$ and 65-75 yrs), race/ ethnicity (White non-Hispanic, Hispanic, African-American and other), sex, educational attainment (high school or less, some college, and college graduate or more), and household income (in increments of US\$20,000, up to US\$80,000). Along with occupational exposure measures, employment status (currently employed and ever employed) and occupational categories for the longest-held job (managerial/professional, technical, sales/administrative, service/ military and skilled trades/agriculture/labourer) were also examined. 


\section{Analyses}

The demographical, socioeconomical and occupational characteristics of respondents with COPD with or without concomitant asthma, those with asthma alone and subjects reporting none of these chronic airway diseases were compared. For ordinal categorical variables, such as household income or education, the differences in the three groups were tested using the Chi-squared test for trend; the Chisquared test was used for all other categorical variables. Analysis of variance was used to test the difference in mean age and duration of occupational exposure (in years) by diagnostic group. For bivariate comparisons of occupational exposures, the COPD group was subdivided into subjects reporting diagnoses of COPD or emphysema with or without concomitant chronic bronchitis and those reporting chronic bronchitis alone. However, the association between diagnostic group and occupational exposure compared all subjects with COPD, broadly defined, to those with asthma alone and those with no chronic airway disease.

For analysis of the associations between COPD and occupational exposure, subjects with asthma alone were included in the general population reference group. All analyses were conducted twice, once using the more comprehensive COPD definition (termed "any COPD") and once using the narrower definition (excluding chronic bronchitis alone). Logistic regression analysis was used to estimate the ORs for COPD for occupational exposure and smoking, first in models containing only the single exposure variables, and then in multivariate models with variables for occupational exposure, smoking, age, sex and race/ethnicity. Measures of socioeconomical status, such as household income or education, were not included because of the causal relationships between occupational status and these variables: educational attainment leading to occupational status leading to income level. The measures of occupational exposure, based either on self-report or occupational matrix, were entered into separate regression models.

Crude and adjusted ORs and 95\% confidence intervals (CIs) were calculated for current and former smoking exposure, and for several measures of occupational exposure, including any self-reported occupational exposure during the longest-held job, the subcategory of exposure (combustion byproducts, inorganic dusts and fumes, and organic dusts versus no exposure) and the probability of dust exposure from the occupational matrix (high and intermediate versus low). In the subcategory analysis, $97(13 \%)$ individuals who self-reported occupational exposure in the screening question were grouped with the reference category (no exposure) because they did not identify any of the exposures in the detailed pre-established list.
Models were estimated that included interaction terms for smoking and self-reported occupational exposure. In these analyses, smoking status was dichotomised as ever versus never smoked. In a separate sensitivity analysis, the effect of completely excluding respondents with asthma alone from the analysis was examined.

In order to estimate the proportion of COPD prevalence attributable to occupational exposures accounting for smoking status, the PAR, an estimate of the proportion of all cases of a disease in a given population that would not have occurred in the absence of the exposure of interest, was calculated. The PAR was estimated from the multivariate logistic models, controlling for smoking, age, sex and race/ ethnicity, following the method of GREENLAND and DRESCHER [26]. This method is derived from the classical definition of attributable fraction (AF):

$$
\mathrm{AF}=1-\operatorname{Pr}(\text { disease given no exposure }) / \operatorname{Pr}(\text { disease })
$$

where $\operatorname{Pr}$ is probability. It takes into account, however, reference or target values of exposure which may vary depending upon the matrix of covariates.

\section{Results}

The final study sample included 377 individuals who reported a physician's diagnosis of at least one COPD, of whom 288 reported chronic bronchitis and 144 emphysema (table 1). Altogether, 140 (37\%) respondents reporting COPD also reported a diagnosis of asthma; an additional 129 individuals reported a physician's diagnosis of asthma but not COPD. By design, the three sampling frames yielded different disease distributions. In the first cohort, the national random sample, and the second cohort, the hot spots sample with and without respiratory disease, 14 and $17 \%$ of respondents, respectively, reported a diagnosis of COPD. Among the three sampling frames, there were no significant differences in the proportion of those with COPD who also reported asthma.

As shown in table 2, the study sample was partitioned into three mutually exclusive groups based on reported diagnoses: COPD (with or without concomitant asthma, $n=377$ ); asthma alone $(n=129)$; and no reported diagnosis of a chronic airway disease $(n=1,555)$. The three groups did not differ significantly in age distribution within the 20 -yr age span of the sample: the mean age of those reporting COPD was $64 \pm 6 \mathrm{yrs}$, asthma alone $63 \pm 6$ yrs and no chronic airway disease $64 \pm 6$ yrs $(\mathrm{p}=0.2)$. Females were over-represented among those reporting COPD and asthma $(\mathrm{p}<0.001)$. Socioeconomical and smoking status also varied significantly by condition group $(\mathrm{p}<0.001)$. Those with COPD had lower levels of education

Table 1.-Health condition (physician-diagnosed) by sampling frame among 2,061 subjects identified by random digit dialling

\begin{tabular}{|c|c|c|c|c|}
\hline & $\begin{array}{c}\text { National } \\
\text { n (\%) }\end{array}$ & $\begin{array}{c}\text { "Hot spots" } \\
\text { n (\%) }\end{array}$ & $\begin{array}{c}\text { "Condition" } \\
\text { n (\%) }\end{array}$ & $\begin{array}{l}\text { Total } \\
\text { n }(\%)\end{array}$ \\
\hline Subjects $n$ & 979 & 976 & 106 & 2061 \\
\hline Any chronic airway disease & $190(19)$ & $210(22)$ & $106(100)$ & $506(25)$ \\
\hline COPD & $135(14)$ & $163(17)$ & $79(75)$ & 377 (18) \\
\hline Emphysema & $54(6)$ & $57(6)$ & $33(31)$ & $144(7)$ \\
\hline Chronic bronchitis & $105(11)$ & $130(13)$ & $53(50)$ & $288(14)$ \\
\hline COPD with concomitant asthma & $53(5)$ & $54(6)$ & $33(31)$ & $140(7)$ \\
\hline Asthma without COPD & $55(6)$ & $47(5)$ & $27(25)$ & $129(6)$ \\
\hline No chronic airway disease & $789(81)$ & $766(78)$ & & $1555(75)$ \\
\hline
\end{tabular}

Specific health conditions are not mutually exclusive, except as indicated for asthma. The national sample was derived by random digit dialling within continental USA. The "hot spots" sample was derived by random digit dialling within higher incidence areas for chronic obstructive pulmonary disease (COPD) based on US mortality data. The "condition" sample was derived from further random digit dialling in the hot spot areas, limiting eligibility to subjects reporting at least one of the target conditions (see Sampling frames and recruitment section). 
Table 2. - Demographical characteristics and smoking status of 2,061 subjects by airway disease diagnosis

\begin{tabular}{|c|c|c|c|c|}
\hline & $\begin{array}{l}\text { COPD } \\
\text { n }(\%)\end{array}$ & $\begin{array}{l}\text { Asthma alone } \\
\text { n (\%) }\end{array}$ & $\begin{array}{c}\text { No chronic airway } \\
\text { disease } \mathrm{n}(\%)\end{array}$ & p-value \\
\hline Subjects $n$ & 377 & 129 & 1555 & \\
\hline \multicolumn{5}{|l|}{ Age yrs } \\
\hline $55-59$ & $106(28)$ & $45(35)$ & $457(29)$ & \multirow[t]{3}{*}{0.6} \\
\hline $60-64$ & $99(26)$ & $32(25)$ & $376(24)$ & \\
\hline $65-75$ & $172(46)$ & $52(40)$ & $722(47)$ & \\
\hline Female sex & $237(63)$ & $88(68)$ & $847(54)$ & $<0.001$ \\
\hline \multicolumn{5}{|l|}{ Race/ethnicity } \\
\hline White non-Hispanic & $326(86)$ & $110(85)$ & $1314(85)$ & \multirow[t]{4}{*}{0.03} \\
\hline Hispanic & $15(4)$ & $9(7)$ & $117(5)$ & \\
\hline Black & $29(8)$ & $4(3)$ & $78(8)$ & \\
\hline Other & $7(2)$ & $6(5)$ & $46(3)$ & \\
\hline \multicolumn{5}{|l|}{ Education } \\
\hline High school or less & $204(54)$ & $47(36)$ & $633(41)$ & \multirow[t]{3}{*}{$<0.001$} \\
\hline Some college & $101(27)$ & $39(30)$ & $486(31)$ & \\
\hline College degree or more & $72(19)$ & $43(33)$ & $436(28)$ & \\
\hline \multicolumn{5}{|c|}{ Household income* US\$ $\cdot \mathrm{yr}^{-1}$} \\
\hline Subjects $n$ & 325 & 113 & 1370 & \multirow{5}{*}{$<0.001$} \\
\hline$<20000$ & $142(44)$ & $31(27)$ & $316(23)$ & \\
\hline $20000-40000$ & $104(32)$ & $35(31)$ & $431(32)$ & \\
\hline $40000-80000$ & $53(16)$ & $25(22)$ & $425(31)$ & \\
\hline$\geqslant 80000$ & $26(8)$ & $22(20)$ & $198(14)$ & \\
\hline \multicolumn{5}{|l|}{ Cigarette smoking status } \\
\hline Never & $73(19)$ & $59(46)$ & $682(44)$ & \multirow[t]{3}{*}{$<0.001$} \\
\hline Former & $183(49)$ & $55(43)$ & $615(40)$ & \\
\hline Current & $121(32)$ & $15(12)$ & $258(17)$ & \\
\hline
\end{tabular}

COPD: chronic obstructive pulmonary disease. *: proportion of missing values $(\mathrm{n}=253)$ did not differ by health condition category $(\mathrm{p}=0.6)$.

and lower household incomes overall, and, as expected, were much more likely to have ever smoked than those with asthma alone or no chronic airway disease. The distribution of smoking status was similar for those with asthma alone and those with no chronic airway disease.

Consistent with a greater degree of work disability associated with COPD relative to asthma, only $19 \%$ of respondents reporting COPD were employed at the time of interview (table 3 ), compared with $30 \%$ of those reporting asthma alone and $31 \%$ of those with no chronic airway disease $(\mathrm{p}<0.001)$. There were no significant differences by diagnosis group in the proportion who had ever been in the labour force $(>90 \%)$ or in the distribution of longest-held job among the major occupational categories. The mean duration of employment in the longest-held job was $19 \pm 11$ yrs among those reporting COPD, $23 \pm 12$ yrs for asthma alone and $22 \pm 12$ yrs for no chronic airway disease $(\mathrm{p}<0.001)$.

As shown in table 4, half of those with COPD reported exposure to VGDF during their longest-held job, compared to $42 \%$ of those with asthma alone and $32 \%$ of those with no chronic airway disease $(\mathrm{p}<0.001)$. Among the 189 subjects with chronic bronchitis alone, $42 \%$ reported VGDF exposure and $57 \%$ of the 188 subjects reporting diagnoses of COPD or emphysema reported VGDF exposure. Each subgroup of exposures (combustion byproducts, inorganic dusts or fumes, and organic dusts) was also reported more frequently by those with COPD, although these differences by diagnostic group were significant only for inorganic dusts and fumes. The three diagnostic groups were compared using a job matrix for occupational exposure likelihood, classifying respondents as having low, intermediate or high probability of dust exposure based on the occupation of their longest-held job. Using this measure, exposure also varied significantly $(\mathrm{p}=0.01)$. Individuals reporting COPD were the most likely to be employed in either intermediate or high probability exposure occupations.

Comparing respondents who did or did not report any COPD diagnosis (regardless of asthma diagnoses), on the basis of self-reported occupational exposure (table 5), VGDF exposure during the longest-held job was associated with a two-fold increase in risk of COPD (OR 2.0, 95\% CI 1.6-2.5).

Table 3.-Occupational characteristics of subjects by airway disease diagnosis

\begin{tabular}{|c|c|c|c|c|}
\hline & $\begin{array}{l}\text { COPD } \\
\text { n }(\%)\end{array}$ & $\begin{array}{c}\text { Asthma alone } \\
\mathrm{n}(\%)\end{array}$ & $\begin{array}{c}\text { No chronic airway } \\
\text { disease } \mathrm{n}(\%)\end{array}$ & p-value \\
\hline Subjects $n$ & 377 & 129 & 1555 & \\
\hline Ever in labour force & $345(92)$ & $120(93)$ & $1412(91)$ & 0.7 \\
\hline Currently employed & $71(19)$ & $39(30)$ & $488(31)$ & $<0.001$ \\
\hline Longest-held job & & & & 0.1 \\
\hline Managerial/professional & $84(22)$ & $44(34)$ & $432(28)$ & \\
\hline Technical & $10(3)$ & $4(3)$ & $34(2)$ & \\
\hline Sales/administration/support & $87(23)$ & $28(22)$ & $396(26)$ & \\
\hline Service/military & $70(19)$ & 17 (13) & $218(14)$ & \\
\hline Manufacture/agriculture/labourer & $94(25)$ & $27(21)$ & $332(21)$ & \\
\hline No labour force participation & $32(8)$ & $9(7)$ & $143(9)$ & \\
\hline
\end{tabular}

COPD: chronic obstructive pulmonary disease. 
Table 4.-Occupational exposure and job exposure matrix (JEM) by airway disease diagnosis

\begin{tabular}{|c|c|c|c|c|c|c|}
\hline & $\begin{array}{c}\text { Chronic bronchitis } \\
\text { alone } \%\end{array}$ & $\begin{array}{c}\text { COPD or } \\
\text { emphysema }{ }^{\#} \%\end{array}$ & Any $\underset{\%}{\mathrm{COPD}}$ & $\begin{array}{l}\text { Asthma } \\
\text { alone } \%\end{array}$ & $\begin{array}{c}\text { No chronic } \\
\text { airway disease \% }\end{array}$ & p-value ${ }^{+}$ \\
\hline Subjects $n$ & 189 & 188 & 377 & 129 & 1555 & \\
\hline Self-reported VGDF exposure ${ }^{\S}$ & 42 & 57 & 50 & 42 & 32 & $<0.001$ \\
\hline Combustion byproducts & 29 & 46 & 37 & 27 & 24 & 0.30 \\
\hline Inorganic dusts or fumes & 23 & 34 & 28 & 16 & 16 & 0.04 \\
\hline Organic dusts & 15 & 23 & 19 & 12 & 11 & 0.38 \\
\hline JEM exposure probability & & & & & & 0.01 \\
\hline Low $^{f^{2}}$ & 69 & 61 & 65 & 76 & 73 & \\
\hline Intermediate & 24 & 26 & 25 & 17 & 19 & \\
\hline High & 6 & 13 & 10 & 7 & 8 & \\
\hline
\end{tabular}

COPD: chronic obstructive pulmonary disease; VGDF: vapours, gases, dusts or fumes. ${ }^{\#}$ : narrower definition of COPD, excluding those with chronic bronchitis alone; ": reported physician diagnoses of emphysema, COPD and/or chronic bronchitis with or without a concomitant diagnosis of asthma; ${ }^{+}$: comparison among any COPD, asthma alone (without COPD) and all others. ${ }^{\$}$ : categories not mutually exclusive (97 individuals reported occupational exposures that did not correspond to any category); ${ }^{f}$ : includes never employed.

The PAR of COPD for self-reported exposure calculated from the logistic regression model was 20\% (95\% CI 13-27\%). On further analysis, the three exposure categories were evaluated separately (data not shown in table). In adjusted models, exposure to inorganic dusts and fumes had the strongest relationship with COPD (OR 1.6, 95\% CI 1.1-2.3), followed by combustion byproducts (OR 1.4, 95\% CI 1.011.9) and organic dusts (OR 1.3, 95\% CI 0.9-1.8).

After controlling for covariates, risk of COPD was elevated for those with intermediate (OR 1.4, 95\% CI 1.1-1.9) and high probability of dust exposure (OR 1.6, 95\% CI 1.1-2.5), according to the job exposure matrix. The combined PAR for intermediate or high probability of exposure was $9 \%(95 \%$ CI $3-15 \%$ ) based on the adjusted models.

As expected, current and former smoking were strongly associated with COPD, resulting in a combined PAR of $51 \%$ (95\% CI 40-59\%), after controlling for age, sex, race, ethnicity and self-reported occupational exposure. The association of smoking exposure and COPD was not substantively different in a model including the occupational exposure matrix variables instead of the self-reported measure.
Table 5 also includes estimates of the risk of COPD defined more narrowly, excluding all 189 subjects with chronic bronchitis alone. In these models, the adjusted OR for selfreported occupational exposure rose slightly to 2.6 (95\% CI 1.8-3.5). For intermediate probability of dust exposure, the adjusted OR was 1.5 (95\% CI 1.04-2.2) and, for high probability of exposure, it was $1.9(95 \%$ CI $1.2-3.2)$. Using the narrower COPD definition, the PAR associated with selfreported exposure was $31 \%$ (95\% CI 19-41\%); the comparable PAR associated with the job exposure matrix was $13 \%(95 \%$ CI 3-22\%). After excluding subjects with bronchitis alone, the PAR for COPD associated with cigarette smoking was much greater, yielding a combined PAR for smoking (current and former) of $76 \%$ in this model.

Since occupational exposures may have affected cigarette smokers and nonsmokers differently, the joint associations of cigarette smoking (ever versus never smoked) and selfreported occupational exposure with COPD were examined, using the definitions with and without chronic bronchitis included. As shown in table 6, the joint association of cigarette smoking and occupational exposure appeared to

Table 5. - Risk of chronic obstructive pulmonary disease (COPD) in relation to cigarette smoking and occupational exposures

\begin{tabular}{|c|c|c|c|}
\hline & Unadjusted OR (95\% CI) & Adjusted OR $(95 \% \mathrm{CI})^{\#}$ & PAR $\%$ \\
\hline \multicolumn{4}{|l|}{ Any COPD } \\
\hline Self-reported VGDF exposure ${ }^{+}$ & $2.0(1.6-2.5)$ & $2.0(1.6-2.5)$ & 20 \\
\hline \multicolumn{4}{|l|}{ JEM exposure probability } \\
\hline Low (referent) & 1.0 & 1.0 & \\
\hline Intermediate & $1.5(1.1-1.9)$ & $1.4(1.1-1.9)$ & 6 \\
\hline High & $1.4(0.98-2.1)$ & $1.6(1.1-2.5)$ & 3 \\
\hline \multicolumn{4}{|l|}{ Cigarette smoking status } \\
\hline Never (referent) & 1.0 & 1.0 & \\
\hline Former & $2.8(2.1-3.7)$ & $2.9(2.1-3.9)$ & 28 \\
\hline Current & $4.5(3.3-6.2)$ & $4.4(3.2-6.1)$ & 22 \\
\hline \multicolumn{4}{|l|}{ COPD or emphysema ${ }^{\S}$} \\
\hline Self-reported VGDF exposure ${ }^{+}$ & $2.7(2.0-3.6)$ & $2.6(1.8-3.5)$ & 31 \\
\hline \multicolumn{4}{|l|}{ JEM exposure probability } \\
\hline Low (referent) & 1.0 & 1.0 & \\
\hline Intermediate & $1.6(1.1-2.3)$ & $1.5(1.04-2.2)$ & 8 \\
\hline High & $2.1(1.3-3.3)$ & $1.9(1.2-3.2)$ & 6 \\
\hline \multicolumn{4}{|l|}{ Cigarette smoking status } \\
\hline Never (referent) & 1.0 & 1.0 & \\
\hline Former & $6.0(3.6-10.0)$ & $5.9(3.5-9.9)$ & 42 \\
\hline Current & $11.0(6.5-18.8)$ & $10.6(6.2-18.4)$ & 34 \\
\hline
\end{tabular}


Table 6. - Independent and joint associations of smoking and occupation with chronic obstructive pulmonary disease (COPD)

\begin{tabular}{lcccc}
\hline $\begin{array}{l}\text { Cigarette smoking status/ } \\
\text { occupational exposure }\end{array}$ & $\begin{array}{c}\text { Subjects } \\
\mathrm{n}\end{array}$ & $\begin{array}{c}\text { Probability } \\
\text { of COPD }\end{array}$ & $\begin{array}{c}\text { Excess }^{\#} \\
\text { Crude } \\
\text { OR }\end{array}$ & $\begin{array}{c}\text { Adjusted OR } \\
(95 \% \text { CI) }\end{array}$ \\
\hline
\end{tabular}

\section{Any COPD $^{+}$}

Never/no

Never/yes

Ever/no

Ever/yes

COPD or emphysema ${ }^{\S}$

Never/no

Never/yes

Ever/no

Ever/yes

589
225
728
519
549
210
659
454

0.08

0.10

0.19

0.32

0.02

0.04

0.11

0.22

$\begin{array}{lr} & 1.0 \\ 0.02 & 1.2 \\ 0.11 & 2.6 \\ 0.23 & 5.0 \\ & \\ & 1.0 \\ 0.02 & 2.1 \\ 0.09 & 6.5 \\ 0.20 & 15.0\end{array}$

1.0

$1.4(0.8-2.3)$

$2.8(2.0-3.9)$

$6.2(4.3-9.0)$

1.0

$2.4(0.9-6.1)$

$7.0(3.6-13.7)$

$18.4(9.3-36.4)$

\#: difference in unadjusted probability of COPD between given exposure level and reference group; rounding error accounts for lack of agreement in some cells. ๆ: adjusted for age, sex, race and ethnicity. ${ }^{+}$: reported physician diagnoses of emphysema, COPD and/or chronic bronchitis with or without a concomitant diagnosis of asthma. \$: narrower definition of COPD, excluding those with chronic bronchitis alone.

be greater than would be expected with a strictly additive relationship. The unadjusted probability of any COPD among those with neither exposure was 0.08 , among those with occupational exposure alone it was 0.10 , among those with smoking exposure alone it was 0.19 and among those with both exposures it was 0.32 . In an additive relationship, the excess risk of COPD for the combination of smoking and occupational exposure (compared to neither exposure) would be approximately equal to the sum of the excess risks for smoking alone and occupational exposure alone. The excess risk for those with both smoking and occupational exposure was nearly twice that: 0.23 compared to 0.13 for any COPD and 0.20 compared to 0.11 for the narrower definition of COPD excluding chronic bronchitis.

As a sensitivity analysis, the multivariate logistic regression models were re-estimated, further excluding the 129 subjects reporting asthma alone, because of the clinical overlap between asthma and COPD. The adjusted OR associated with self-reported occupational exposure in this subsample was $2.1(95 \%$ CI 1.6-2.7) and the resulting PAR was $21 \%$ (95\% CI $14-28 \%)$.

\section{Discussion}

The present findings support an association between COPD and occupational inhalant exposures. Increases of $>100 \%$ in the risk of COPD due to workplace factors were observed, even after taking into account the impact of cigarette smoking. Since some degree of exposure was relatively common, the proportion of COPD contributed by occupation was considerable, with an estimated PAR of 20 or $31 \%$, depending upon the definition of COPD used. In other words, elimination of all adverse workplace exposures could prevent more than one in five cases of COPD, all other risk factors (including cigarette smoking) being equal.

The risks estimated in the present study are in the range of those reported by other investigators. VIEGI and Di PEDE [10] concluded from their literature review that $\sim 15 \%$ of all COPD could be attributed to occupational exposures. The studies yielding this estimate were heterogeneous in approach. Furthermore, few were designed a priori to focus on occupation as a risk factor for COPD using a populationbased approach and studying older adults at greatest risk of disease. It is also interesting to note that the PAR estimated in the present study is similar to that found for asthma in relation to occupational VGDF exposure [27].

The present survey method, despite the advantages of broadbased recruitment of subjects, has important limitations. The retrospective nature of the study may lead to the introduction of recall bias, to the extent that affected individuals may associate their conditions with exposure. However, the job exposure matrix, which would not be prone to this bias, reaffirmed the association between occupation and disease.

The standard epidemiological approach of self-report of a physician's diagnosis of one of three conditions (chronic bronchitis, emphysema or COPD) to define COPD was used. The National Health and Nutrition Examination Survey (NHANES) found a $12.5 \%$ US national prevalence of reported physician diagnosis of emphysema or chronic bronchitis (a "COPD" diagnosis was not queried) among adults aged 55-75 yrs [28], compared to the $13.5 \%$ found in the present national sampling frame.

This epidemiological approach, although widely used, can lead to overestimations due to attribution of diagnoses that were not made or were made erroneously. Similarly, this approach to case definition can lead to underestimations due to poor access to medical care or missed diagnoses despite medical evaluation. One recent study documented that only a minority of subjects reporting a physician's diagnosis of chronic bronchitis also meet a symptom-based case definition [29]. Another study, however, found that, among those reporting the diagnosis and yet with questionnaire-based symptoms falling short of a probable or definite classification of chronic bronchitis, $79 \%$ nonetheless demonstrated airway obstruction [30]. In another recent study regarding this question, self-report of a physician's diagnosis of COPD, as defined in the present study, was shown to be a potent predictor of airflow obstruction [31]. Thus, although using a reported diagnosis without confirmation by pulmonary function testing leads to some overdiagnosis, this case definition appears to be valid for epidemiological purposes and is supported by other studies.

Under-reporting of disease may be a more common problem. A recent analysis of NHANES III data found that only $63 \%$ of subjects with low lung function (forced expiratory volume in one second (FEV1)/forced vital capacity of $<0.70$ or FEV1 of $<80 \%$ of the predicted value) reported a physician's diagnosis of asthma, chronic bronchitis or emphysema [32]. The extent to which COPD is similarly under-reported in the present study, however, is unlikely to be differentially related to exposure and thus would bias results towards the null hypothesis. Such misclassification may account for the relatively low PAR for smoking that was observed on analysis of the entire cohort (51\%), although, after excluding those with chronic bronchitis alone, the resulting PAR of $76 \%$ is closer to the $80-90 \%$ range generally cited [33].

The role of cigarette smoking appears to be complex. In the present analyses, evidence was found for an interaction between smoking and occupational exposures, such that 
current or former smokers reporting job exposure were at particularly high risk of COPD. Other studies have found similar relationships $[10,11,34]$. This is biologically plausible, since irritant gas and particulate exposures could interact in either additive or multiplicative ways in the initiation and progression of chronic bronchitis, emphysema or airflow obstruction. Moreover, the differences in attributable risk to PAR for both occupation and smoking, estimated with or without subjects with chronic bronchitis, are consistent with heterogeneity in the causal pathways of diseases subsumed within the overall category of COPD.

Cigarette smoking remains the predominant aetiological factor in chronic obstructive pulmonary disease and is appropriately at the forefront of public health efforts in lung disease prevention. Nonetheless, the present findings support and extend the observations of other studies, indicating a significant role of some occupations in causing chronic obstructive pulmonary disease. Clinicians and healthcare policy-makers need to take workplace conditions into account, perhaps all the more so among smokers, when targeting prevention strategies.

\section{References}

1. Anto J, Vermeire P, Vestbo J, Sunyer J. Epidemiology of chronic obstructive pulmonary disease. Eur Respir J 2001; 17: 982-994.

2. Murray C, Lopez A. Evidence-based health policy - lessons from the Global Burden of Disease Study. Science 1996; 274: 740-743.

3. National, Heart, Lung and Blood Institute, World Health Organization. Global Initiative for Chronic Obstructive Lung Disease: a Collaborative Project of the National, Heart, Lung and Blood Institute and the World Health Organization. Bethesda, National Institutes of Health, 2001.

4. Greenhow E. Chronic bronchitis especially as connected with gout, emphysema, and diseases of the heart. London, Longmans, 1868.

5. Fletcher C. Disability and mortality from chronic bronchitis in relation to dust exposure. AMA Arch Ind Health 1958; 18 : 368-373.

6. Goodman N, Lane R, Rampling S. Chronic bronchitis: an introductory examination of existing data. $B M J 1953 ; 4830$ : 237-243.

7. Becklake M, Dupreez L, Lutz W. Lung function in silicosis of the Witwatersrand gold miner. Am Rev Tuberc Pulm Dis 1958; 77: 400-412.

8. Stoeckle J, Hardy H, King W, Nemiah J. Respiratory disease in U.S. soft coal miners: clinical and etiological considerations. J Chronic Dis 1962; 15: 887-905.

9. Becklake M. Occupational exposures: evidence for a causal association with chronic obstructive pulmonary disease. $\mathrm{Am}$ Rev Respir Dis 1989; 140: Suppl. 3, 85-91.

10. Viegi G, Di Pede C. Chronic obstructive lung diseases and occupational exposure. Curr Opin Allergy Clin Immunol 2002; 2: 115-121

11. Zock J, Sunyer J, Kogevinas M, Kromhout H, Burney P, Anto J. Occupation, chronic bronchitis, and lung function in young adults. An international study. Am J Respir Crit Care Med 2001; 163: 1572-1577.

12. Fishwick D, Bradshaw L, D'Souza W, et al. Chronic bronchitis, shortness of breath, and airway obstruction by occupation in New Zealand. Am J Respir Crit Care Med 1997; 156: 1440-1446.

13. Sunyer J, Kogevinas M, Kromhout H, et al. Pulmonary ventilatory defects and occupational exposures in a population-based study in Spain. Am J Respir Crit Care Med 1998; 157: 512-517.

14. Humerfelt S, Gulsvik A, Skjaerven R, et al. Decline in FEV1 and airflow limitation related to occupational exposures in men of an urban community. Eur Respir J 1993; 6: 1095-1103.

15. Krzyzanowski M, Kauffmann F. The relation of respiratory symptoms and ventilatory function to moderate occupational exposure in a general population. Int J Epidemiol 1988; 17: $397-406$

16. Bakke P, Baste V, Hanoa R, Gulsvik A. Prevalence of obstructive lung disease in a general population: relation to occupational title and exposure to some airborne agents. Thorax 1991; 46: 863-870.

17. Krzyzanowski M, Jedrychowski W. Occupational exposure and incidence of chronic respiratory symptoms among residents of Cracow followed for 13 years. Int Arch Occup Environ Health 1990; 62: 311-317.

18. Korn R, Dockery D, Speizer F, Ware J, Ferris B Jr. Occupational exposures and chronic respiratory symptoms: a population-based study. Am Rev Respir Dis 1987; 136: 298-304.

19. Lebowitz M. Occupational exposures in relation to symptomatology and lung function in a community population. Environ Res 1977; 14: 59-67.

20. Kim J. Atlas of Respiratory Disease Mortality, United States: 1982-1993. Cincinnati, Dept of Health and Human Services, National Institute for Occupational Safety and Health, 1998; pp.23-25.

21. US Bureau of the Census. Industry and Occupation Classification System. Washington, DC, US Dept of Commerce, 2000

22. US Bureau of the Census. Current Population Survey Technical Documentation. Washington, DC, US Dept of Commerce, 1993

23. United Medical and Dental Schools of Guy's and St Thomas' Hospitals, Dept of Public Health Medicine. Protocol for the European Community Respiratory Health Survey. London, United Medical and Dental Schools St Thomas' Campus, 1993.

24. Blanc P, Ellbjar S, Janson C, et al. Asthma-related work disability in Sweden. The impact of workplace exposures. Am J Respir Crit Care Med 1999; 160: 2028-2033.

25. Kovar M, Poe G. The National Health Interview Survey design, 1973-1984, and procedures, 1975-1983. Vital Health Stat 1 1985; 18: 82-83.

26. Greenland S, Drescher K. Maximum likelihood estimation of the attributable fraction from logistic models. Biometrics 1993; 49: 865-872.

27. Kogevinas M, Anto JM, Sunyer J, Tobias A, Kromhout H, Burney P. Occupational asthma in Europe and other industrialised areas: a population-based study. Lancet 1999; 353: $1750-1754$

28. National Center for Health Statistics. Plan and Operation of the Third National Health and Nutrition Examination Survey, 1988-1994. Washington, DC, US Dept of Health and Human Services, 1994.

29. Bobadilla A, Guerra S, Sherrill D, Barbee R. How accurate is the self-reported diagnosis of chronic bronchitis? Chest 2002; 122: 1234-1239.

30. Barr RG, Herbstman J, Speizer FE, Camargo CA Jr. Validation of self-reported chronic obstructive pulmonary disease in a cohort study of nurses. Am J Epidemiol 2002; 155: 965-971.

31. Straus SE, McAlister FA, Sackett DL, Deeks JJ. Accuracy of history, wheezing, and forced expiratory time in the diagnosis of chronic obstructive pulmonary disease. $J$ Gen Intern Med 2002; 17: 684-688.

32. Mannino DM, Gagnon RC, Petty TL, Lydick E. Obstructive lung disease and low lung function in adults in the United States: data from the National Health and Nutrition Examination Survey, 1988-1994. Arch Intern Med 2000; 160: 1683-1689.

33. US Dept of Health and Human Services. The Health Consequences of Smoking: Chronic Obstructive Lung Disease. A Report of the Surgeon General. Rockville, US Government Printing Office, 1984.

34. Hnizdo E, Baskind E, Sluis-Cremer G. Combined effect of silica dust exposure and tobacco smoking on the prevalence of respiratory impairments among gold miners. Scand J Work Environ Health 1990; 16: 411-422. 